\title{
Improving Family Medicine with Thoughtful Research
}

\author{
Anne Victoria Neale, PhD, MPH, Marjorie A. Bowman, MD, MPA, \\ and Dean A. Seebusen, MD, MPH
}

This issue is about improving primary health care outcomes, from behavioral health to opioid issues to diagnosing hypertension to providing hope for childhood obesity. It includes hints for integrating behavioral health and care managers into family medicine practices. Opiate prescribing practices vary considerably between Japan and the United States, with helpful insights for our opiate abuse epidemic. Suicidality is high among patients taking opiates. Diagnosing hypertension the recommended way is not easily accomplished. Primary care clinicians are important in infertility and prostate cancer treatment, and in support of men who commit interpersonal violence and people with cognitive impairment who wander. The "July effect" seems to persist. Parents' views on obesity in children can be changed—for the better. Family physicians have less burnout than has been previously reported, and many provide palliative care. Doctors think diseases, patients think about how well they feel. Do we find healthy lifestyles in retirement? (J Am Board Fam Med 2017;30:117-120.)

\section{Expanded Care Practices}

This issue contains 2 articles on integrating new care team members into expanded care practices. First, in a follow-up to the supplement issue on integrated behavioral health, Balasubramanian et $\mathrm{al}^{1}$ provide examples of patient improvements in integrated practices. Having a behavioral health clinician on site and readily available can make a large difference for some patients, and it saves time for medical providers working through mental health issues. Second, care managers are joining patient-centered primary care teams, but they may find bumps in the road to being well-accepted or integrated into the practice. Malouin et $\mathrm{al}^{2}$ also describe a process for acceptance of care managers in the 3-year Michigan Primary Care Transformation demonstration project that was successful regardless of practice size or specialty.

\section{Learning from Japan on Opiates and Suicidality Associated with Illicit Drugs}

Large and telling differences exist between opioid prescribing in the United States and Japan. Opioids are used much less often for both acute and chronic

Conflict of interest: The authors are editors of the $7 A B F M$. pain in Japan. Onishi et $\mathrm{al}^{3}$ report many interesting findings from a survey of physicians, suggesting some methods that could be considered to decrease opioid use in the United States. In another article on drug use, Hallgren et $\mathrm{al}^{4}$ report high incidence and predictors of suicidal ideation and suicide attempt among primary care patients who reported use of illicit drugs or nonprescribed medications within the past 90 days. Read the article to see the many single-predictor associations of variables with suicidal ideation (incidence, 26\%) and suicide attempt (incidence, $7 \%$ ) over the 12-month followup. The majority who attempted or completed suicide interacted with primary care providers within the previous 6 months, providing the opportunity to screen for suicidality among high-risk substance users.

\section{Screening and Prevention}

Nagykaldi et $\mathrm{al}^{5}$ provide importance guidance on strategies to improve the content of conversations stemming from health risk assessments (HRAs) at annual wellness visits. A low-intensity, multicomponent intervention resulted in several positive changes in the quality of these conversations, plus patients felt more informed, empowered, and mo- 
tivated by the HRA-enhanced wellness visits. Clinicians also found assistance from the HRA report.

Apparently, it is not easy to follow the US Preventive Services Task Force (USPSTF) recommendations for accurate hypertension diagnosis. Woolsey et $\mathrm{al}^{6}$ examined hypertension diagnosis practices relative to the USPSTF recommendations. A total of 123 clinics participated (38\% response rate); compliance with USPSTF varied from $58 \%$ to $94 \%$. Only $25 \%$ reported access to ambulatory monitoring, and 37\% had instructions for home blood pressure monitoring.

\section{Fitwits $^{\text {TM }}$}

Given the extent of our childhood obesity problem, it is wonderful to see a relatively simple, straightforward intervention ${ }^{7}$ that helps parents understand their child's level of obesity and changes behavior. For more background information, see also previous $7 A B F M$ articles about Fitwits ${ }^{8,9}$

\section{Health Services Research}

The so-called "July effect" is well known to providers in teaching hospitals; July is the month when new medical residents begin training, replacing the experienced, graduating residents. Mims et $\mathrm{al}^{10}$ used the Nationwide Inpatient Sample (NIS) data set to explore mortality rates among patients admitted to teaching hospitals during the first quarter of the academic calendar. Study data suggested a small yet significant increase in mortality for patients with myocardial infarction admitted to teaching versus nonteaching hospitals during the first academic quarter compared with all other quarters. Increased cost and length of stay were also identified for those admitted with heart failure.

Using data from the 2013 American Board of Family Medicine Maintenance of Certification Examination Demographic Survey, Ankuda et $\mathrm{al}^{11}$ explored the scope of the practice of palliative care. One third of family physician respondents reported providing palliative care, particularly non-clinicbased services, including at nursing homes, home visits, and hospice care.

\section{Self-Reported Health}

Elder et $\mathrm{al}^{12}$ explored patient and physician reasoning, as well as the roles played by patient lifestyle and objective health measures, in the congruence between patient self-rated health (SRH) and physician-rated patient health $(\mathrm{PRPH})$. The patient- physician dyad reasons for health status rating and for needed health improvements matched approximately $25 \%$ of the time, yet these matches were not associated with SRH or PRPH. As many would predict, physicians tended to focus on disease (ie, the number and severity of conditions) in their reasoning for most patients, whereas those patients with high SRH focus on feeling well. Results support the need for shared decision making, as physicians cannot assume they know how patients perceive their own health.

Continuity of care, particularly with patients experiencing multiple chronic conditions, is a cornerstone of primary care, yet the benefits of care continuity are difficult to validate. Bayliss et $\mathrm{al}^{13}$ analyzed baseline and 2-year follow-up data. $\mathrm{Pa}$ tient-reported outcomes were consistent over the 2 -year period but were not associated with continuity of care at baseline or follow-up.

Is retirement associated with healthier lifestyle? King et $\mathrm{al}^{14}$ used nationally representative crosssectional data from the National Health and $\mathrm{Nu}-$ trition Examination Survey to explore lifestyle and health indicators using the American Heart Association's Life's Simple 7 cardiovascular risk factors. Retirees and nonretirees were similar on most risk factors. An exception is that retirees were more likely to have poorly controlled blood pressure; however, they were also more likely to be physically active.

Physician burnout is reportedly increasing and may affect patient care or workforce turnover. As described in a report from the American Board of Family Medicine, ${ }^{15}$ the Mini $Z$ burnout survey was administered to a sample of family physicians applying to take the 2016 Family Medicine Certification Examination. With a $100 \%$ response rate, a lower prevalence of this problem was identified compared with other studies, which may suggest nonresponse bias in other reports; that is, it is possible that physicians who felt burnout were more likely to answer the other surveys. Overall, these findings are reassuring.

\section{Family Medicine's Impact on Treatment Decision Making}

Jiang et $\mathrm{al}^{16}$ undertook qualitative research with men facing decisions about which type of specialist to choose for prostate cancer treatment. The type of specialist seen can make a difference in which 
treatment is offered and accepted, as the current treatments have differing side effect profiles but entail similar patient mortality. Many men relied on their primary care physician and diagnosing urologist for referrals. This is an important opportunity for family physicians to counsel patients about the different treatment perspectives and likely outcomes, facilitating informed decisions about prostate cancer treatment, partially through suggesting consultations for a second opinion.

Boltz et $\mathrm{al}^{17}$ explored the association between patient-reported initial clinician type (generalist vs subspecialist) seen by infertile women, and the type of treatment received and time to live birth. The first point of contact for most women was a generalist provider; these women were less likely to receive in vitro fertilization, yet were equally likely to achieve pregnancy and had similar times to pregnancy compared with women who presented first to a subspecialist.

Much has been written about the victims of intimate partner violence, yet less is known about the men who perpetrate such violence on their partners. Penti et $\mathrm{al}^{18}$ provide an interesting qualitative study, presenting the voices of physicians who care for such men. Sometimes physicians care for both partners and learn of the intimate partner violence from the abused women; other times the men bring it up to the doctor. Physicians voice uncertainty about how to begin the conversation and how best to help these male patients. Physicians are also concerned about how to avoid increasing the violence. See the article for suggested recommendations based on the conversations and the literature.

\section{Ethics Feature}

Cognitive impairment is common among the elderly and is related to potentially dangerous wandering. Location trackers are a strategy to increase patient safety and reduce caregiver burden. Balancing the safety and autonomy of cognitively impaired persons entails more than evaluating decision-making capacity. Yang et $\mathrm{al}^{19}$ review the ethical issues raised by electronic monitoring of cognitively impaired individuals, providing a patient-centered framework for different stages of decline.

To see this article online, please go to: http://jabfm.org/content/ 30/2/117.full.

\section{References}

1. Balasubramanian BA, Cohen DJ, Jetelina KK, et al. Outcomes of integrated behavioral health with primary care. J Am Board Fam Med 2017;30: 130-39.

2. Malouin JM, Malouin RA, Sarinopoulos I, et al. Physician and staff acceptance of care managers in primary care offices. J Am Board Fam Med 2017;30: 140-49.

3. Onishi E, Kobayashi T, Dexter E, Marino M, Maeno T, Deyo RA. Comparison of opioid prescribing patterns in the United States and Japan: primary care physicians' attitudes and perceptions. J Am Board Fam Med 2017;30:248-54.

4. Hallgren KA, Ries RK, Atkins DC, Bumgardner K, Roy-Byrne P. Prediction of suicide ideation and attempt among substance-using patients in primary care. J Am Board Fam Med 2017;30:150-60.

5. Nagykaldi ZJ, Dave A, Kristof CJ, Watts TN, Utpala S, Wickersham E. Improving patient-clinician conversations during annual wellness visits. J Am Board Fam Med 2017;30:161-69.

6. Woolsey S, Brown B, Ralls B, Stults B, Friedrichs M. Diagnosing hypertension in primary care clinics according to current guidelines. J Am Board Fam Med 2017;30:170-7.

7. Edwards BA, Powell JR, McGaffey A, et al. Fitwits ${ }^{\text {TM }}$ leads to improved parental recognition of childhood obesity and plans to encourage change. J Am Board Fam Med 2017;30:178-88.

8. McGaffey A, Abatemarco DJ, Jewell IK, Fidler SK, Hughes K. Fitwits $\mathrm{MD}^{\mathrm{TM}}$ : an office-based tool and games for conversations about obesity with 9- to 12-year-old children. J Am Board Fam Med 2011; 24:768-71.

9. Jortberg BT, Rosen R, Roth S, et al. The Fit Family Challenge: a primary care childhood obesity pilot intervention. J Am Board Fam Med 2016; 29:434-43.

10. Mims LD, Porter M, Simpson KN, Carek PJ. The "July effect": a look at July medical admissions in teaching hospitals. J Am Board Fam Med 2017;30: 189-95.

11. Ankuda CK, Jetty A, Bazemore A, Petterson S. Provision of palliative care services by family physicians is common. J Am Board Fam Med 2017;30:255-7.

12. Elder N, Imhoff R, Chubinski J, et al. Congruence of patient self-rating of health with family physician ratings. J Am Board Fam Med 2017;30:196-204.

13. Bayliss EA, Ellis JL, Shoup JA, McQuillan DB, Steiner JF, Zeng C. Association between continuity of care and health-related quality of life. J Am Board Fam Med 2017;30:205-12.

14. King DE, Xiang J. Retirement and healthy lifestyle: a National Health and Nutrition Examination Survey (NHANES) data report. J Am Board Fam Med 2017;30:213-9. 
15. Puffer JC, Knight HC, O’Neill TR, et al. Prevalence of burnout in board-certified family physicians. J Am Board Fam Med 2017;30:125-6.

16. Jiang T, Stillson CH, Pollack CE, et al. How men with prostate cancer choose specialists: a qualitative study. J Am Board Fam Med 2017;30: 220-9.

17. Boltz MW, Sanders JN, Simonsen SE, Stanford JB. Fertility treatment, use of in vitro fertilization, and time to live birth based on initial provider type. J Am Board Fam Med 2017;30:230-8.

18. Penti B, Tran H, Timmons J, Rothman EF, Wilkinson J. Physicians' experiences with male patients who perpetrate intimate partner violence. J Am Board Fam Med 2017;30:239-47.

19. Yang YT, Kels CG. Ethical considerations in electronic monitoring of the cognitively impaired. J Am Board Fam Med 2017;30:258-63. 